\title{
Campos entre Taipas e Aramados: Novos olhares sobre a paisagem serrana Catarinense.
}

\section{Fields between Taipas and wire mesh: New Looks about the landscape Serrana Catarinense}

\author{
Cristiane Fortkamp Schuch ${ }^{1}$
}

\begin{abstract}
Resumo: A importância dos estudos sobre a paisagem tem por base as interações de seus vestígios na história, sendo a percepção e o olhar os vetores de transmissão de significados, apresentando se como imagem, no limiar entre a existência física e mental. Desta forma, o presente artigo propõe se a elaborar um exercício de análise sobre a história dos campos do planalto serrano catarinense, compreendendo que a natureza transformada pela ação humana é consequência de relações materiais, mas também simbólicas que grupos humanos com o meio ambiente, de maneira que os lugares nos quais estão inscritas as existências humanas foram construídos pelos homens, ao mesmo tempo pela sua ação técnica e pelo discurso que mantinham sobre ela, o que os torna reflexivos e produtos de diferentes experiências culturais.
\end{abstract}

Palavras Chave: Paisagem, Cultura, Memória

\begin{abstract}
The importance of the estudies about landscape has by based the interations of its traces in de history, being the perception and the look of the vectors of the steraming of the meanigs, shoning it as images in the fhreshold betwen the physical existence and mental. This way, the article proposes elaborate an exercise of analyse about the history of the fields of the Santa Catarina plateu, comprising that the nature transformed by human is the consequence of the material relatitions but also simbolic that human groups as the enviroment the way that the places wrich are written in the human existences were but by man, at the sometime by its technical action and by the reported that keep about tis what il became reflexive and product's of cultural diferentt experiences.
\end{abstract}

Key Words: Landscape, Culture, Memory

A história da ocupação dos campos do Planalto Serrano Catarinense ${ }^{2}$ marcou a relação entre o olhar humano e a construção da memória ao longo do tempo. O diálogo entre passado e presente nas estruturas da organização sócio espacial regional remetem à formação de valores culturais e sentidos simbólicos à paisagem, num processo de ressignificação da natureza. Neste sentido, a importância dos estudos sobre a paisagem tem por base as interações de seus vestígios na história, sendo a memória o vetor de transmissão de significados, e também de reconfigurações que permitiram distintas formas de reapropriação da natureza.

\footnotetext{
${ }^{1}$ Doutora em Geografia pela UFSC, atualmente cursando Doutorado em História pela mesma instituição. cris.fortkamp@gmail.com

${ }^{2}$ Planalto Serrano Catarinense é considerado o vasto território de campos e bosques de Araucária angusti-folia, popularmente denominada de "pinheiro brasileiro", árvore predominante nas regiões do Planalto Sul brasileiro. Está situado no estado de Santa Catarina, acima das encostas da Serra Geral, junto à divisa com o estado do Rio Grande do Sul. Aí lhe são contíguos os Campos de Cima da Serra, de características similares, e com os quais fazem divisa, de leste para oeste, os municípios catarinenses de Bom Jardim da Serra, São Joaquim, Lages, Capão Alto, Campo Belo do Sul, Cerro Negro e Anita Garibaldi.
} 
De acordo com a ideia sociológica de Latour é possível refletir sobre a atuação de um conjunto de protagonistas humanos e não humanos que definem uma antropologia da modernidade. Esta é entendida como um processo simétrico entre a organização social, a natureza e o discurso humano. Em sua obra "Jamais fomos modernos", o autor postula uma articulação hibrida entre estas esferas, de forma que é impossível conceber a relação entre sociedade e meio ambiente como um projeto de dominação pela qual a natureza não é elemento passivo (LATOUR, 1991.p.22).

Desta forma, ao problematizar as relações entre paisagem, cultura e memória no processo de ocupação e utilização dos campos no Planalto Serrano Catarinense, a natureza se apresenta como característica fundamental na construção dos saberes e nos projetos de desenvolvimento regionais.

Tomando por base os estudos de Maurice Halbawachs, a memória e a história são geradoras de espaços de saberes diferenciados, mas a interpretação entre as duas instâncias enrique a historiografia. (HALBAWACHS, 2015.p.59). Neste mesmo sentido, José D’Assunção Barros ressalta a importância da memória (sendo ela individual ou coletiva) como uma instância criativa, de produção simbólica, capaz de instituir identidades e assegurar a permanência de grupos, territorializando sua existência. (BARROS, 2009.p.37).

Assim também, pensando a paisagem como um elemento da relação histórica entre os homens e a natureza, e portanto, produtora de cultura, é possível descrever o período entre os primeiros anos da colonização e o século XVIII como de configuração e organização do espaço com a finalidade de desenvolver uma estrutura produtiva baseada na utilização das áreas de pastagens naturais, o que torna as características ambientais determinantes deste sistema. Contudo, este processo também evidencia relações de poder que invisibilizam determinados grupos, e atribui status social a outros. Neste sentido, vale ressaltar a definição de Marcelo Lopes de Souza, para qual o território é definido e delimitado por e a partir de relações de poder, que deve ser apreendido em múltiplas vertentes com diversas funções, que engendram materialidades que constituem seu fundamento econômico e sua base cultural. (SOUZA, 2001.p.108).

Ao estudar aspectos da ocupação territorial e suas transformações ao longo do tempo, o espaço é conceituado como a união entre a configuração territorial, a paisagem e a sociedade. Milton Santos aborda esta questão afirmando que ao longo da história da humanidade podem as formas, durante muito tempo, permanecer as mesmas, mas como a sociedade está sempre em movimento, a mesma paisagem, 
a mesma configuração territorial, nos oferecem, no transcurso histórico, espaços diferentes. (SANTOS, 1996, p. 77).

Assim, na configuração territorial definida pelas atividades econômicas no Planalto Serrano Catarinense, destaca se neste artigo as transformações territoriais ocorridas a partir do desenvolvimento da atividade pecuária, instalada como economia subsidiária no período colonial brasileiro, e que originalmente se instalou no nordeste brasileiro, mas foi transferida para o interior, para que não ocupasse e danificasse os espaços destinados aos canaviais, assim sendo responsável pela abertura de novas áreas de povoamento da colônia portuguesa (BOLDRINI, 2002. p. 129).

Sob o ponto de vista das condições ambientais, as formações campestres que poderiam ser destinadas a criatórios são encontradas em todos os biomas brasileiros, mas até o século XVIII, sua predominância se deu no bioma Pampa e no Bioma Campos de Altitude da Mata Atlântica, no sul do Brasil.

Esta afirmação, além de descrever a importância da atividade para o desenvolvimento e expansão econômica e territorial do Brasil Colonial, através do abastecimento do mercado interno com couro e carne destinados diretamente as áreas de produção para exportação, além de animais para força de tração, como os centros produtores de açúcar, ouro, algodão, e mais tarde o café, também permite compreender como determinados projetos de desenvolvimento econômico foram responsáveis por um processo de reorganização regional com objetivo de atender demandas econômicas nacionais e internacionais, redefinindo as relações sociais e moldando novos olhares sobre a paisagem dos campos.

No que reflete à utilização dos campos do sul brasileiro, Barbosa os historiciza argumentando que "iniciou-se com mais intensidade a partir de 1701, quando uma proibição real forçou a transferência dos criatórios para uma distância de no mínimo dez léguas das lavouras de cana-de-açúcar”. Esta transferência foi responsável, em parte, pelos conflitos estabelecidos entre a Coroa Portuguesa e Espanhola e os Jesuítas. Estes, já ocupavam a região desde os primeiros anos da colonização, objetivando catequizar a população indígena e estabelecendo princípios culturais, sociais e religiosos europeus em território colonial. Formaram reduções independentes, através da organização do trabalho agrícola e da criação de rebanhos de gado solto, possibilitando reservas para suas estâncias. Em 1688, quando os Portugueses fundam Laguna, tem-se início as atividades comerciais com a Colônia do Sacramento, e estas atividades passaram a ser objeto de disputa entre diversos setores sociais. (BARBOSA,1978. p. 93) 
Neste sentido, a questão dos limites e das fronteiras entre as Coroas Portuguesa e Espanhola acentuam as tensões existentes naquele território. Primeiramente o Tratado de Madri estabelecia, em 1750, uma permuta entre a Colônia do Sacramento, dos portugueses, e os Sete Povos das Missões, dos espanhóis. Mas em consequência dos conflitos um novo tratado foi assinado em 1777. Era o Tratado de Santo Idelfonso que devolveu o território dos Sete Povos para os espanhóis. A partir dele, os limites de fronteira ficaram estabelecidos na região que hoje compreende Santa Vitória do Palmar e o Chuí, sendo que nesta área de fronteira se criou os "Campos Neutrais", ou seja, um espaço a ser respeitado pelas duas Coroas.

De acordo com Osvaldo André Oliveira, o processo de colonização gradativamente expulsou os indígenas que ocupavam estas terras, desenvolvendo a exploração mercantilista através do apresamento e da comercialização das cabeças de gado xucro existentes no território. (OLIVEIRA, 2010. p. 67). Somente em 1801 que a questão dos limites territoriais entre as duas Coroas foram estabelecidos, através do Tratado de Badajós, que retomou a divisão estabelecida em 1750.

Com a chegada dos bandeirantes, os jesuítas se retiraram deste território, levando os nativos para a outra margem do Rio Uruguai, deixando rebanhos de gado xucro que formaram as "Vacarias del Mar". A Vacaria do Mar estava num território que pertencia ao Rei de Espanha, pois a partir de 1640, com o termino da União da Coroa Ibérica, o suposto Tratado de Tordesilhas voltava à tona. Todavia o território era administrado pelos padres da Companhia de Jesus.

Fugindo de espanhóis e portugueses, o padre jesuíta Lauro Nunes fundou, em 1702, a "Vacaria dos Pinhais", transferindo a atividade pecuária para os campos de cima da serra, e moldando as bases da economia regional neste território. Assim, os primeiros rebanhos de gado desenvolveram-se no sul do Brasil através dos rebanhos transferidos pelos Jesuítas das Vacarias del Mar (Pampa Gaúcha) para os campos de Cima da Serra, formando as Vacarias Del Piñar, protegidos ao norte e nordeste pelos Aparados da Serra e ao oeste, sudoeste e sul pelo Mato Castelhano e o Mato Português.

De acordo com Walter Piazza, partir da abertura do caminho do Sul e da então decisão do Governador da Capitania de São Paulo de fundar uma povoação no "Sertão de Curitiba" em 1776, por razões estratégicas dentro do contexto do relacionamento luso-espanhol, houve um esvaziamento econômico da vila de Laguna, de modo que se abriu um caminho acompanhando o curso do rio Tubarão em direção à vila fundada por Correia Pinto (PIAZZA, 1983, p.78). Deste modo, o povoamento do 
Planalto acelerou-se, num processo de ocupação marcado por "invernadas", "pousos” e "estâncias", e posteriormente através da concessão de sesmarias.

Após expulsos os jesuítas, os rebanhos de gado sem dono ficaram entregues à própria sorte, até que luso-açorianos provenientes de Laguna adonaram-se deles e instalaram as suas estâncias nos Campos de Cima da Serra (COSTA, 1982, p. 1463). O território que hoje compreende os campos de Lages e de Curitibanos passou a ganhar importância a partir da definição dos limites e fronteiras no período colonial. Segundo Licurgo Costa (1982), os portugueses, após garantirem São Francisco, Ilha de Santa Catarina e Laguna, iniciaram a colonização das terras de Viamão, tornando necessária a abertura de caminhos terrestres, criando áreas de abastecimento de tropas de mulas, cavalos e gado vacum, para o abastecimento de São Paulo, Minas e mesmo o norte da colônia (COSTA, 1982, p. 31).

Por consequência, o tropeirismo também foi responsável pela caracterização da estrutura social das primeiras vilas e cidades do Planalto Serrano Catarinense. A partir da abertura de estradas, paulistas e lagunenses fundaram as primeiras fazendas e estâncias de criação, antes mesmo da fundação da Vila de Lages por Correia Pinto (COSTA, p.15). Aluisio de Almeida afirma que o bandeirante paulista soube "aclimatar-se" a uma situação de vida ainda primitiva, selvagem, que para devassarem o interior do país, contavam como o bugre com os recursos da fauna e da flora selvagem (ALMEIDA, 1945. p.152). Surgem a partir de então, os primeiros fazendeiros da região, ganhando status e notoriedade no desenvolvimento da economia local.

Assim, a organização do espaço para esta finalidade foi marcada, neste mesmo período, pela construção das taipas ${ }^{3}$, construídas em grande medida, por mão de obra escrava, negra ou indígena. Sua existência evitava que os animais das tropas se dispersassem no campo, se misturassem ao rebanho existente nas fazendas, ou se perdessem. O mesmo material era utilizado muitas vezes para delimitar os espaços e locais de trabalho, como a sede da fazenda, galpões e mangueiras. A divisão de espaços demarca fisicamente os espaços sociais, de trabalho e de lazer destas propriedades.

Segundo a pesquisa realizada para o diagnóstico do patrimônio arqueológico, histórico-cultural, paleontológico e de educação patrimonial na área destinada ao aproveitamento hidrelétrico da Usina Hidrelétrica Pai Querê, estas estruturas que formam as taipas do Planalto Serrano Catarinense foram construídas com formas e acabamentos diferenciados, e não necessariamente conectados entre si, o que

${ }^{3}$ A taipa corresponde a muros construídos com pedras dispostos de forma paralela, separando propriedades ou, na forma de corredores, evitando que o gado em transito se disperse pelos campos. 
sugere a construção baseada em mão-de-obra de particulares, por proprietários de terras às margens do caminho, onde e como melhor fossem, em áreas que não tivessem barreiras naturais, como rios, encostas íngremes, etc. (HEBERTZ, 2012, p.44). Da mesma forma, se percebe traços da cultura negra e cabocla na formação social e espacial de territórios campesinos. As primeiras fazendas de criação formaram-se a partir da construção de uma hierarquia social baseada na obtenção da propriedade de terras e escravos. De um lado se comercializava o produto da terra - o gado engordado nos vastos campos naturais - e de outro, a propriedade se mantinha através da posse e perpetuação do status formado conforme as condições naturais pertinentes no território. Embora o número de escravos, se comparado ao nordeste açucareiro e ao sudeste minerador fosse de menor expressão, a pecuária extensiva foi uma das atividades econômicas que acentuou a maior distribuição de mão de obra escrava na província de Santa Catarina.

Também vale ressaltar que não há registros oficiais sobre a construção dos corredores, o que reforça a inexistência de um planejamento integrado na sua construção. No entanto, trata-se de construções próprias do século XVIII, que imprimiram na paisagem as características da utilização do espaço. Neste sentido, as arqueólogas Luciana Ribeiro e Tânia Tomazia afirmam que:

As taipas representam um traço cultural marcado pelo conhecimento das condições ambientais dos locais, pois foi um espaço pensado também no sentido das escolhas realizadas de traçado e a necessidade ou não de construir corredores ou outras estruturas. Houve uma reflexão sobre onde instalar, como e por que construir. Havia muitas circunstâncias a serem observadas: Inclinação do terreno, existência de hidrografias, tipo de solo, grau de erosão e a proximidade dos recursos como água e pastagem, ou pontos de pouso. (TOMAZIA; RIBEIRO, p. 55 .In: HEBERTZ, 2012).

Em outras palavras, estes estudos demonstram a marca do olhar humano sobre a paisagem como produtor de cultura, uma vez que a paisagem é composta, modificada ou transformada de acordo com a projeção das necessidades humanas. Tomando por base que a paisagem percebida é também construída, vale ressaltar a importância das histórias de vida que ergueram os projetos de organização do território e deixaram suas marcas na paisagem. São os assim chamados taipeiros, construtores e sujeitos históricos muitas vezes invisibilizados pela historiografia.

Os taipeiros, de acordo com Octacílio Schuler Sobrinho, evidenciam o conhecimento e o trabalho do homem caboclo - "homem de aspecto rude, magro, mascador de fumo (...) mas de olho apurado e com uma sensibilidade dimensional fantástica, pois ao colocar a pedra seguinte, olha para as demais deixadas pelo aprendiz e vai direto àquela que permite um encaixe adequado" (SCHULER SOBRINHO, 2000 p.03). 
Este mesmo historiador, ao descrever as origens do homem da Guerra do Contestado, afirma que o caboclo é a representação nativa e miscigenada, que não possui identidade étnica, mas que se encontra em várias regiões do Brasil, pois rompeu obstáculos geográficos, povoando montes, vales e horizontes (op.cit.p.14). Especialmente na região do Planalto Serrano Catarinense seus hábitos culturais são diversificados, deixando traços de sua cultura na paisagem. No entanto, sua representação social foi negada no processo de ocupação do território. Indígenas e negros foram segregados na composição política, econômica, social e cultural do Planalto Serrano Catarinense, o que se explica em parte pela ideologia de branqueamento do século XX, que previa a elaboração de uma ideia de nação brasileira mais branca, desconsiderando as heterogeneidades, inferiorizando e marginalizando, sobretudo, exescravos. (ARRUDA, 1972.p. 56).

Fig. 1 - Taipas. No detalhe, corredores construídos nos campos da "Coxilha Rica"- Lages.

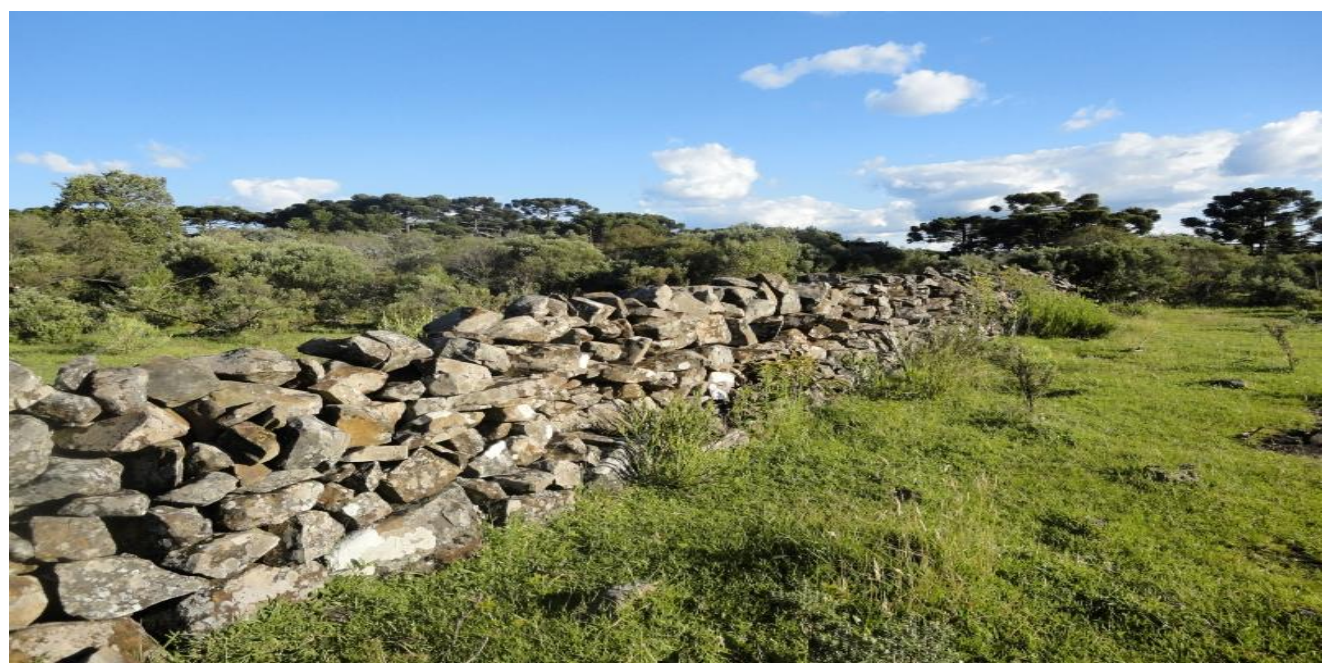

Fonte: BAMPI, Ricardo. 2007.

Ao observarmos a imagem acima podemos ver alguns detalhes que permitem valorizar o conhecimento geográfico e ambiental de seus construtores das taipas. Ela tem a base mais larga do que o topo, tendo a forma de uma pirâmide, quando vista de cima. Encaixadas umas nas outras de maneira precisa, formam um quadro abstrato que pode ser visto ao longo de todo seu comprimento, já que não há uma pedra igual à outra. A cada metro quadrado de taipa, um padrão de formas, ranhuras, reentrâncias e saliências. Musgos, liquens e alguma gramínea fazem a composição de cores para compor o quadro. 
$\mathrm{Na}$ diversidade de formas e encaixes das pedras cria-se uma unidade que se torna sólida, longeva e imponente na paisagem.

Fig. 2 - Taipas. No detalhe, corredores construídos nos campos da “coxilha rica”- Lages

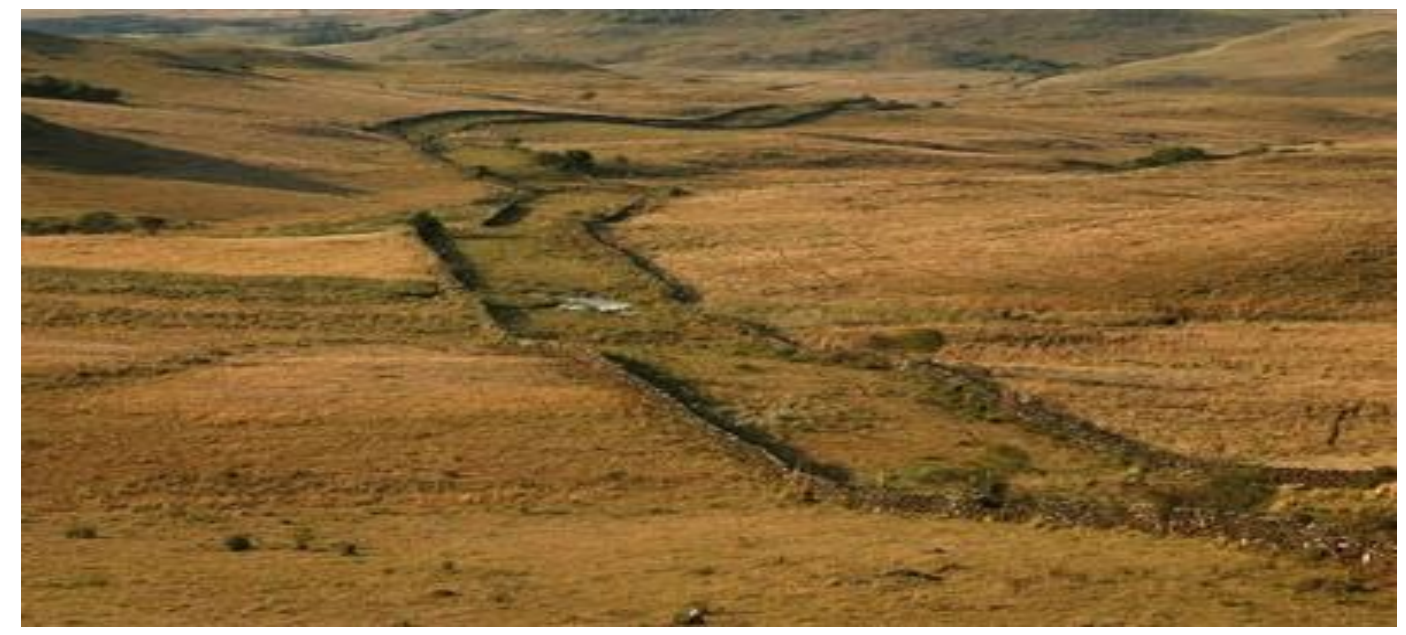

Fonte: BAMPI, Ricardo. 2007.

Erguidas monumentalmente entre as áreas de campos, florestas e fazendas de criação que foram modificadas ela ação humana, sua importância estrutural foi diminuindo à medida que a o arame e o mourão de madeira ou pedra tornaram se materiais mais baratos e disponíveis no mercado ao longo da segunda metade do século XIX. Contudo, as taipas converteram se num importante símbolo de construção da identidade regional. Ao longo de seus corredores, foram inscritas memórias e experiências que compõem diferentes percepções da paisagem, e que preservam traços da cultura material e imaterial de diferentes sujeitos históricos, e sua relação com os campos de criação.

Levando em consideração que é por intermédio de um espectador que um lugar natural torna se uma imagem, e que nossa percepção está diretamente condicionada a nossa cultura, entende se que os campos naturais adquiriram o valor de pastagens, mas sua paisagem revela outras variantes de pesquisa, que incluem diferentes formas de pensar o espaço, seja por vias econômicas, socioculturais e/ou políticas. Ainda segundo Antônio Carlos Robert Moraes, há uma valorização subjetiva do espaço que define a humanização e a apropriação da natureza, ao afirmar que:

O espaço produzido é um resultado da ação humana sobre a superfície terrestre que expressa, a cada momento, as relações sociais que lhe deram origem. Neste sentido a paisagem manifesta a historicidade do desenvolvimento humano, associando objetos fixados ao solo e geneticamente datados. Tais objetos exprimem a espacialidade de organizações sociopolíticas específicas e se articulam sempre numa funcionalidade do presente (MORAES, 1996.p.15) 
Assim também as corredeiras dos rios que cortam os campos do planalto serrano catarinense serviram de referência para os primeiros traços de caminhos pelos quais uma nova classe social - os ricos fazendeiros - se desenvolveu e se tornou representativa no estado de Santa Catarina, ocupando vastas áreas de campos nativos entremeados por mata de araucárias, abrindo longas vias de comercialização de animais para serem vendidos nas feiras de Sorocaba, em São Paulo.

Aluisio de Almeida afirma que a abertura destas estradas e caminhos era tratada pelos paulistas com o termo "descortinar", ou seja, cortar o mato e abrir passagem em qualquer lugar (ALMEIDA, 1945. p.25).

Fig. 3 - Passo de Santa Vitória, Coxilha Rica. Lages.

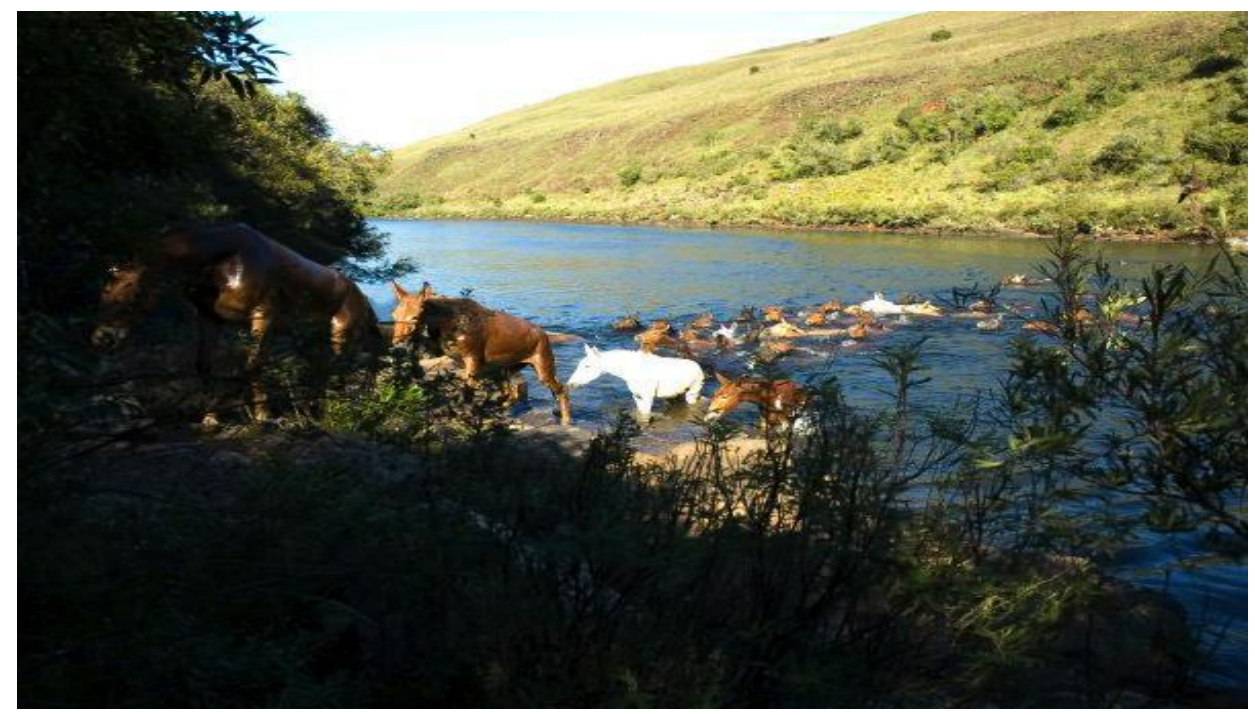

Fonte: BAMPI, Ricardo.2007

A imagem acima é uma representação da passagem de tropas pelo Passo de Santa Vitória. Localizado no Rio Pelotas, demarca a divisa entre o Rio Grande do Sul e Santa Catarina. Localizado na localidade da Coxilha Rica. Além de ser o ponto de travessia de tropeiros Bom Jesus (RS) para Lages (SC) em direção à Viamão e Sorocaba entre os séculos XVIII e XIX, funcionou também como posto de cobrança, além de funções variadas, como arrecadação de tributos sobre produtos e animais, e controle do trânsito de pessoas, evitando a passagem de desertores, e delimitação geográfica entre estruturas administrativas (SILVA, 2006. p. 78). Aberto em 1773 por Cristóvão Pereira de Abreu e desativado em 1848, o Passo de Santa Vitória foi tombado como patrimônio cultural pelos munícipios de Lages e Bom Jesus na década de 1990. Por tratar se de um remanescente patrimonial do tropeirismo, tornou se importante símbolo da cultura serrana, marcada pela formação social latifundiária. 
A Coxilha Rica, traduzida do espanhol, significa terreno ondulado limpo e bonito. Foi a localidade do Planalto Serrano Catarinense por onde ergueram se a maior parte dos corredores de tropas e, por consequência, onde surgiram as sedes de pousos e fazendas, desenvolvendo outros espaços de interações sociais, como povoados, igrejas, cemitérios e bodegões. Este território é também a maior área de campos naturais com matas de araucárias, rios e riachos preservados do estado catarinense, correspondendo à $43 \%$ da área do município de Lages, sendo destacada pelo IPHAN de Santa Catarina como um dos mais importantes acervos paisagísticos do Ciclo do Tropeirismo no Brasil.

O arranjo formado pela combinação dos corredores de taipas, passos, fazendas e cemitérios históricos com os campos de altitude, que marca o que se convencionou chamar de Paisagem Cultural do Tropeirismo. Além da relevância histórica, constitui uma associação de singular apelo estético e ambiental.”(SILVA, 2006. p. 12).

Contudo, não podemos confundir a paisagem com imagem e memória. Essa segunda é muito mais um pulsar, um momento, a qual, num conjunto, pode instituir paisagens. No entanto, a imagem, pode estar associada também ao lugar enquanto uma primeira consciência espacial (HOLZER,1997.p. 67). Neste contexto, os sentidos atribuídos a paisagem dependem de duas dimensões específicas: A primeira - da paisagem vivida, em que os seus elementos configuraram se como ferramentas de apropriação do espaço e delimitação de fronteiras, compondo a dinâmica das relações econômicas e das relações entre diferentes grupos sociais. E a segunda - da paisagem simbólica, onde o olhar participa da experiência emotiva e, por vezes, estética que se tem dos lugares, através da memória. (CLAVAL, 1999. p.83). Esta, por sua vez, projeta se para a reflexão de lugares concretos impregnados de subjetividades.

Esta diferenciação do olhar sobre a paisagem enquadra se em três momentos distintos da história da utilização dos campos no Planalto Catarinense. O primeiro é determinado pela formação das primeiras fazendas de criação, caracterizando a propriedade particular e dos rebanhos de gado que passaram a movimentar a economia regional. O segundo momento caracteriza o desenvolvimento da pesquisa e das políticas públicas voltadas ao desenvolvimento da atividade e ao melhoramento do produto destinado à comercialização. O terceiro consiste na análise das políticas de preservação pensadas para o mesmo território, tomando por base interesses individuais e públicos que compõem o processo de ressignificação da paisagem na segunda metade do século XX, e que permitiram a formação de áreas naturais protegidas, especialmente na região dos campos da Coxilha Rica em Lages. 
O fim da escravidão, o declínio do tropeirismo e o avanço das técnicas de produção provocaram, a partir do século XIX, um processo de transição econômica ao mesmo tempo em que redefine as relações sociais e a habitação humana, além de impulsionar a construção e a reconstrução de territórios.

Há uma alteração destas variáveis, à medida que a ocupação e a organização social da região sofrem alterações relativas à densidade populacional e ao cercamento de propriedades que delimitam o espaço do rebanho por propriedade. Neste sentido, vale a compreensão de como as mudanças relativas ao sistema de produção alteraram também a organização das fazendas tradicionais de criação.

Desta forma, o território organizado e reorganizado ao longo do tempo torna-se o ponto de referencia para interpretar a dinâmica das relações socioeconômicas e as diferentes formas de compreender os limites e as autonomias de diversos sujeitos sociais em relação à utilização do meio natural, bem como a ideia que diferentes grupos fazem sobre o domínio da natureza, pontuando mudanças e permanências ao longo dos três séculos que compõem a análise deste estudo.

Segundo a análise da estrutura demográfica, social e econômica da Vila de Lages entre 1798 e 1808, há um significativo aumento do número de agregados nas propriedades, o que pode ser explicado pela charqueadas, e também pela procura de carne bovina pelos habitantes do litoral da Província de Santa Catarina. Como consequência direta, as ricas propriedades do Planalto exploravam o trabalhador pobre, tornando a região uma mescla de elementos humanos de origem étnica variada: Em menor número o branco rico, que era proprietário de terras e o político local; ademais, escravos, negros forros, índios e brancos pobres que viviam em torno do seu senhor, que estabelecia uma relação paternalista onde um relacionamento supostamente familiar atenuava as diferenças sociais entre senhores e servos (EHLKE, 1973.p.76).

Fig. 4 - Fazenda Cruz de Malta, casa de Correia Pinto

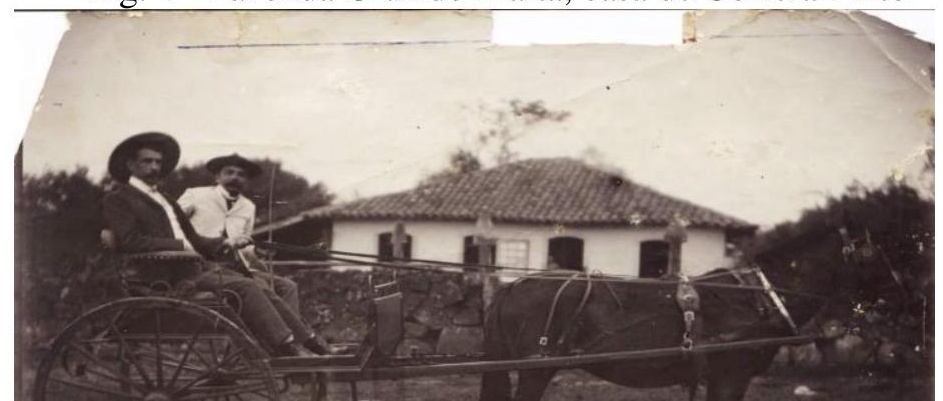


Fonte: Museu Thiago de Castro - Lages-SC

No desenvolvimento da atividade pecuária no século XIX parecem definir-se dois tipos de fazendeiros: Aqueles que aderiram as ideias modernizantes, e outros que permaneceram com as técnicas tradicionais de criação. Portanto, o processo de desenvolvimento econômico local não foi homogêneo, tornando importante compreender a formação da sociedade rural Lageana como fator preponderante, uma vez que as aspirações de classe e a vocação política estão diretamente relacionadas à posse de terras e gado. Assim também os campos do planalto serrano catarinense podem ser estudados sob a ótica das transformações estruturais que foram consequência de diferentes arranjos socioeconômicos ao longo de sua ocupação, bem como das diferentes formas pelas quais o olhar humano imprimiu sua significação.

Observando a imagem da Fazenda Cruz de Malta, erguida por volta de 1770 pelo mestre construtor paulista Caetano Saldanha, que acompanhava a comitiva do fundador do povoado que hoje corresponde à Cidade de Lages Antônio Correia Pinto, podemos identificar diferentes traços de cultura que compuseram a arquitetura das Fazendas do Planalto Serrano Catarinense. Com aparência externa em alvenaria, esta sede foi construída com uma técnica conhecida como pau a pique. Fabiano Teixeira dos Santos, ao estudar a estrutura arquitetônica dos campos de Lages no século XVIII e XIX, assim descreve esta construção:

O pau-a-pique consistia na montagem de uma estrutura em madeira, à semelhança das casas em madeira, com pilares enterrados no chão (origem da expressão "pau-a-pique"); essa estrutura era vedada com tramas de fibra vegetal amarradas ou pregadas (lascas de taquara, palmeira ou sarrafos de madeira), por sua vez revestidas com barro aplicado manualmente, daí o fato de também ser denominada "taipa de mão". Ao final recebia uma fina camada de revestimento de cal, para efeito de acaba- mento e pintura, sendo vulgarmente denominado de estuque e bastante usado para levantar as paredes internas das residências. (SANTOS, 2015.p.91). 
De acordo com o mesmo autor, esta técnica tem sua origem nas construções tradicionais portuguesas e evidenciam os arranjos culturais marcados pela relação entre o Planalto Serrano Catarinense e o Ciclo do Tropeirismo até o século XIX. Mas assim como as imagens são ressignificadas de acordo com as fronteiras que separam épocas, culturas e experiências de mundo, também a paisagem natural adquire significações diversas de acordo com o significado pessoal e/ou coletivo que a experiência imaginal ou o lugar de memória.

A alvenaria foi introduzida em terras brasileiras já nos primeiros anos da colonização. No entanto, o conhecimento do território foi definindo diferentes formas de utilização dos recursos naturais. Os inúmeros afloramentos de basalto e arenito estimularam a construção de algumas moradias. No entanto, a madeira de araucária, encontrada de forma abundante no Bioma mata Atlântica tornou se o material de mais fácil obtenção para construção de casas, forros, esquadrias e móveis. Ainda de acordo com Fabiano Teixeira dos Santos, o Código de Posturas da Cidade de Lages de 1895, proibiu que as construções fossem inteiramente confeccionadas em madeira, devendo o material restringir-se, externamente, às paredes laterais e posteriores. Ou seja, ao menos a fachada frontal das casas deveria obrigatoriamente ser construída em alvenaria de tijolos ou pedras, principalmente no meio urbano, por tratar se de material mais resistente e seguro. (SANTOS, 2015. p.81).

De acordo com Sartre, quando o espaço se torna objeto de apreensão, passa a ser imagem na imaginação, dotando de sentido e valor o que é apreendido pelo olhar. (SARTRE, 1984.p.67). Esta analogia entre imagem e paisagem permite compreender como a natureza, apropriada e transformada pelo homem, passa a representar lascas de memória individual e/ou coletiva, que projetam intencionalmente suas percepções na organização espacial em que estão inseridas. Neste sentido, as imagens exprimem intenções, visões de mundo e projetos de organização socioespacial que as incluem num contexto especifico de análise da ciência histórica, pois há de se considerar o contexto do lugar e o intuito para qual foram elaboradas. Em outras palavras, cabe ao historiador também compreender a natureza da imagem. (Didi-Huberman, 1998. p. 181).

Conforme os estudos da antropologia da imagem amplamente analisada por Hans Belting, o olhar humano projeta sobre o objeto suas impressões subjetivas (sonhos, imaginações, percepções pessoais), que compõem o significado corpóreo e/ou simbólico ao meio, tornando-se objeto da história da representação, na produção do conhecimento. 
Desta forma, a história dos campos do planalto serrano catarinense sofreram o impacto de relações materiais, mas também simbólicas que grupos humanos com o meio ambiente, de maneira que os lugares nos quais estão inscritas as existências humanas foram construídos pelos homens, ao mesmo tempo pela sua ação técnica e pelo discurso que mantinham sobre ela, o que os torna reflexivos. Os homens concebem seu ambiente como se houvesse um espelho que, refletindo suas imagens, os ajuda a tomar consciência daquilo que eles partilham (CLAVAL, 1999b.p.11).

Para o geógrafo Milton Santos, a paisagem é definida como o domínio do visível (...). A dimensão da paisagem é a dimensão da percepção humana, sendo um processo seletivo de apreensão. (SANTOS, 1979, p. 68). Desta forma, o espaço organizado e reorganizado ao longo do tempo torna-se o ponto de referência para interpretar a dinâmica das relações e as diferentes formas de compreender os limites e as autonomias de diversos sujeitos sociais em relação à utilização do meio natural, bem como este compreende e percebe a natureza a partir de sua cultura.

De acordo com Hans Belting, as imagens podem ser analisadas como um conjunto de símbolos, através dos quais podemos compreender processos de permanência, transição, transformação e reconstrução de territórios. O declínio do tropeirismo, o avanço das áreas destinadas à pecuária extensiva no centro oeste brasileiro e as políticas públicas de desenvolvimento rural no final do século XIX tornaram inevitável o processo de reconstrução da paisagem nos campos de altitude do Brasil meridional, alterando as características estruturais da sociedade e do ambiente natural com o desenvolvimento de novas técnicas de criação de gado, desenvolvidas a partir da atuação de instituições políticas que influenciaram na estabilidade econômica da região e nas motivações por vezes conflitantes de seus indivíduos.

Exemplo singular deste processo de transformação foi a introdução de novas técnicas de demarcação de territórios. O arame liso chegou aos campos de altitude do Brasil a partir de 1870 e o arame farpado só aportou por aqui lá pelo ano de 1913, importado dos EUA, de onde surgiu em escala industrial em 1873. 
Fig. 5 . Cerca de Arame Farpado (Aramado). Lages.

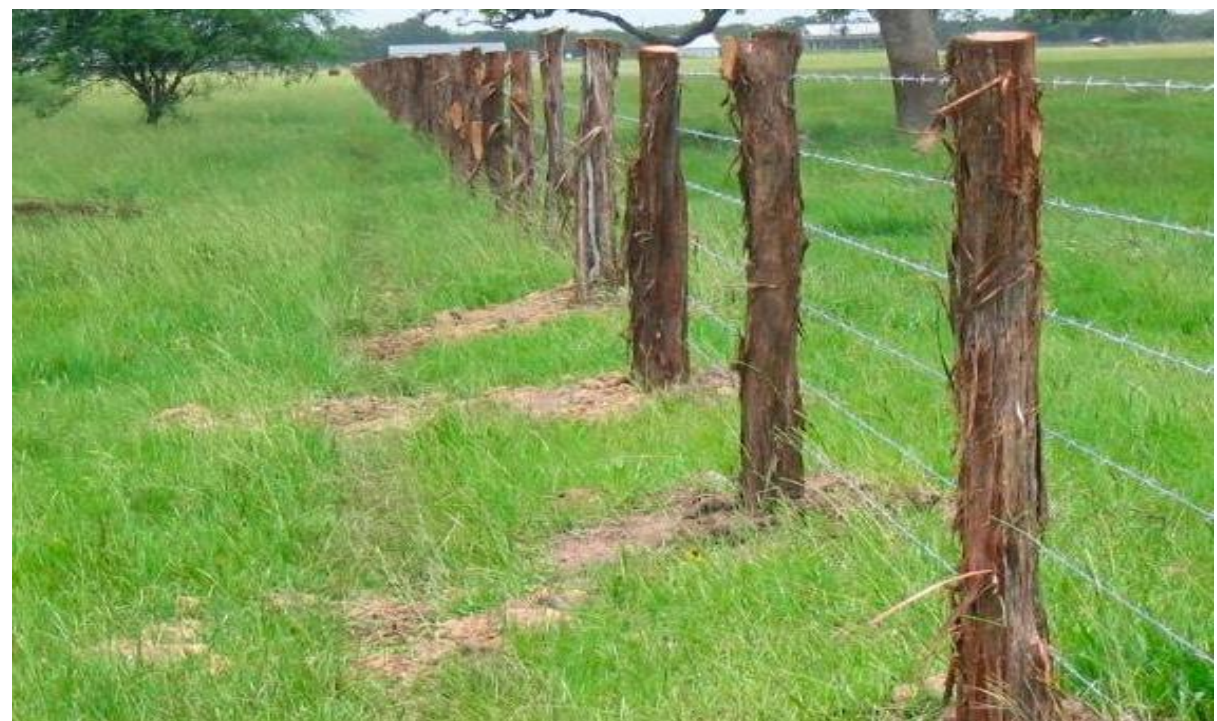

Fonte: http://www.lagesdiario.com.br. Acesso em 09/10/2017.

Esta analise permite também a utilização de duas dimensões propostas por Reinhart Koselleck (2006) para compreender como passado e futuro possuem relações multifacetadas. O território aqui definido constitui se como um espaço de experimentação. $\mathrm{O}$ velho e o novo passam a compor a paisagem e ao mesmo tempo, ambos servem às novas formas de compreender interesses públicos e privados na constituição de uma nova racionalidade produtiva, sem que esta tenha resultado numa ruptura estrutural. A imagem do campo enquanto área constitutiva da identidade pode assim ser reavaliada, a partir do século XX, como um território que abriga múltiplas paisagens, historicamente construídas, e que passaram a abrigar diversas formas de compreender e utilizar os recursos naturais, bem como transformá-los em decorrências das atividades econômicas assim estabelecidas. Além de tornarem se símbolo da cultura regional, as taipas passaram a coexistir e serem adaptadas às novas exigências da pecuária enquanto atividade econômica. A foto abaixo registra a composição da paisagem a partir desta sobreposição de elementos constitutivos da organização do espaço: 
Fig. 6- Taipas e Aramados - Lages/SC

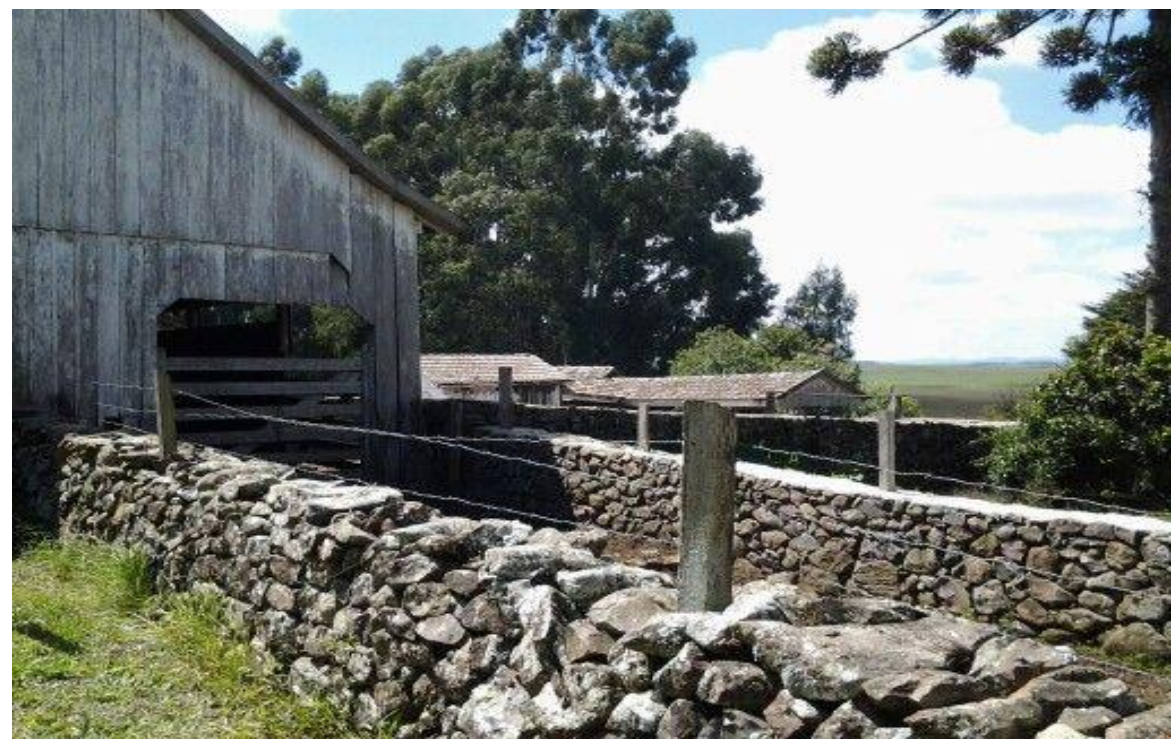

Fonte: Acervo da autora. 2012.

Assim, sendo o território um elemento de identidade (MORAES, 1996. p. 96), vale ressaltar que estas transformações podem ser analisadas também nos campos catarinenses também sob o ponto de vista da paisagem enquanto representação tangível e invisível dos valores socioculturais regionais.

Os projetos de modernização da pecuária passaram a caracterizar as ações de políticas públicas, desencadeando novos processos produtivos e novas relações econômicas ligadas à pecuária e a utilização dos campos de altitude do Planalto Catarinense, bem como as transformações no modo de produção e a ampliação das atividades também embasaram as relações sociais.

Esse projeto de dinamização da economia tem sua gênese marcada pela criação da Estação Experimental de Lages, em que a pesquisa, divulgação e implantação de novas tecnologias permitiram remodelar as relações de produção, de modo a tornar-se referência nos projetos de sustentabilidade técnico-produtiva, concretizando as formas dinâmicas de cooperação entre as organizações públicas e o desenvolvimento econômico da sociedade civil. Entre estas determinações destaca-se a substituição de mão de obra por meio de máquinas e instrumentos "apropriados", a aquisição de melhores sementes e 
renovos de plantas, e o melhoramento de raças de animais úteis, promovendo a generalização das melhores espécies ${ }^{4}$. (Silva apud Santos, 1998, p. 46).

Neste sentido, a criação da Estação Experimental e do Posto Zootécnico de Lages desencadearam transformações tanto na qualidade dos rebanhos, quanto na cultura de forrageiras, reorganizando a atividade pastoril no Planalto Catarinense. De acordo com os relatórios encaminhados pelo Posto Zootécnico desde a sua fundação em 1913, também fazia parte da finalidade básica de sua atuação, além do melhoramento pastoril e aclimatação de raças, inserirem métodos de trabalho que pudessem racionalizar as atividades do homem no campo pela adoção de sistemas que tornassem a exploração pastoril mais econômica e lucrativa ao proprietário rural. Também exerceu profunda influência na disseminação de métodos de criação, como a construção de piquetes e estábulos para o confinamento do gado, a utilização de vacinas contra diversas doenças, a criação de banheiros sanitários e a utilização de insumos para a melhoria da qualidade do gado, que gradativamente transformou e estrutura produtiva de muitas fazendas.

Este período coincide com o processo que Peluso Júnior chama de "evolução da paisagem cultural", que decorre do aumento de terras ocupadas pela lavoura, por parte da população que não dispõe de campos para criação de gado (op.cit., p.153). O pioneirismo no cruzamento de raças europeias, bem como na utilização ou difusão de técnicas de criação e manejo, pode ser associado aos projetos de fomento na área da pecuária extensiva, levando-se em conta que a partir do século XIX a maior parte dos fazendeiros dos campos de Lages passou a converter suas propriedades em estabelecimentos de produção mista, investindo capital em outras atividades.

A partir do terceiro quartel do século XIX, mesmo com a decadência da mineração, o gado bovino e equino continuou sendo requisitado pelos mercados paulistas e mineiros, atendendo as demandas das fazendas de café. Neste mesmo período, as fazendas dos campos de Lages, Campos Novos e Curitibanos proliferaram-se e adquiriram boa estrutura.

\footnotetext{
${ }^{4}$ A criação da Estação Agronômica do Estado de Santa Catarina, pela Lei Estadual no 166 de 29 de setembro de 1895, permitiu de certa forma a ampliação de seus objetivos, contemplando e incentivando a pesquisa em um grande leque de produtos, incluindo, entre outros, grãos, frutíferas, forrageiras, atividades florestais e atividades alternativas de modo que foram criadas Estações Experimentais e Postos Zootécnicos para atender outras regiões do Estado, incluindo neste contexto o Posto Zootécnico de Lages. Sobre este assunto recomenda se o trabalho de: SANTOS, Lucy Woellner. Estação Agronômica e de Veterinária do Estado: (1895-1920)- Uma abordagem histórica sobre o início da pesquisa agrícola em Santa Catarina. Florianópolis: Ed. UFSC, 1998.
} 
Neste sentido, a paisagem manifesta a historicidade do desenvolvimento humano, associando objetos fixados ao solo e geneticamente datados. (MORAES, 1996. p.15). Há uma maior agregação do valor do trabalho ao solo, de forma que as intervenções técnicas são produtos de projetos elaborados com base no incentivo à introdução de outras espécies forrageiras, por razão econômica, em prol de um modelo econômico que transformasse o latifúndio pastoril do Planalto Catarinense conforme o padrão das estruturas capitalistas da época.

No entanto, há de se refletir sobre os fatores adversos a este processo, uma vez que a modernização da pecuária e de suas estruturas produtivas não foi percebida da mesma forma por todos os proprietários rurais, desenvolvendo-se duas formas de criação num mesmo espaço. Aquelas que permaneceram extensivamente em campos nativos, e aquelas que substituíram os campos nativos pelas pastagens plantadas e o gado comum pelos cruzamentos com raças europeias.

Contudo, ao historiar a ressignificação dos campos de altitude como espaço produtivo, entende se estes também como um espaço de experiência, onde as práticas estabelecidas e as teorias de desenvolvimentos a ele atribuídas conferem novas características convergentes ou não com práticas anteriores, sendo, portanto, um território de expectativas que ligam diferentes gerações em torno de projetos que reclassificam a relação entre o homem e o ambiente natural no tempo e no espaço. (KOSELLECK, 2006.p.309).

A apropriação dos antigos campos nativos do planalto catarinense para conversão em áreas de pastagens cultivadas, monoculturas agrícolas, áreas de reflorestamento, mineração e empreendimentos para geração de energia são alvo de amplas discussões. Os campos, bem como todos os vestígios materiais que se relacionam aos antigos caminhos de tropas, passaram a figurar como estruturas visíveis que possuem profunda relação com um mundo suprassensível que só pode ser contemplado através da imagem. Especialmente no que diz respeito aos campos da Coxilha Rica, devido ao seu potencial hídrico e eólico, atualmente discute se os projetos para implantação de complexos de geração de eletricidade que serão responsáveis por uma nova alteração da paisagem e consequente extinção de boa do patrimônio paisagístico e arquitetônico que lhe confere

Assim, o reflexo imagético da composição formada pela taipas, campos e antigas fazendas de criação compõe signos icônicos ou figurativos que estabelecem códigos de representação de uma identidade regional que, mesmo composta por estruturas sociais heterogêneas, consolida a ideia de herança e pertencimento local. O significado que adquirem os objetos do mundo natural na perspectiva 
do olhar humano sobre a paisagem convergem com as reinterpretações de suas relações ao longo do tempo, bem como determinam as representações, intervenções e transformações projetadas para aquele espaço. Esta intima dependência perceptível na forma como a humanidade projeta sua relação com a natureza é destacada na poesia "Achadouros”, de Manoel de Barros:

Acho que o quintal onde a gente brincou é maior do que a cidade. A gente só descobre isso depois de grande. A gente descobre que o tamanho das coisas há que ser medido pela intimidade que temos com as coisas. Há de ser como acontece com o amor. Assim, as pedrinhas do nosso quintal são sempre maiores que as outras pedras do mundo. Justo pelo motivo da intimidade (...) Mas eu estava a pensar em achadouros de infâncias. Se a gente cavar um buraco ao pé da goiabeira do quintal, lá estará um guri ensaiando subir na goiabeira. Se a gente cavar um buraco a pé do galinheiro, lá estará um guri tentando agarrar no rabo de uma lagartixa. Sou hoje um caçador de achadouros de infância. Vou meio dementado e enxada às costas a cavar no meu quintal vestígios dos meninos que fomos(...). (BARROS, 2003).

Os valores e ideais expressos na memória e descritos na poesia produzem um olhar poético sobre a ressignificação da paisagem enquanto imagem, que no tempo e no espaço ao longo da história, vincula se a representações e experiências que diluem as fronteiras que separam épocas e culturas. Ela exprime a ideia de permanência, transição ou transformação, através da construção de sua imagem enquanto herança, conectando o presente e o passado na construção de símbolos que não estão necessariamente ligados a percepção do cotidiano, mas que produzem vínculos contínuos no imaginário social e na construção da ideia de patrimônio. Assim, há uma representação imagética da vida, só permitida através da relação entre o olhar e a experiência contida na memória.

\section{Referências bibliográficas}

ALMEIDA, Aluísio de. Caminhos do sul e a feira de Sorocaba. Revista do Instituto Histórico e Geográfico Brasileiro. RJ: UFRJ, 1945.

ARRUDA, Gilmar (org.). A natureza dos rios: História, memória e territórios. Curitiba: UFPR, 2008.

ARRUDA, Indalécio. Revivendo o Passado. Rio de Janeiro: Planejamento Gráfico, 1972.

ARRUDA FILHO, José Maria. Coisas do Passado. Lages, Santa Catarina. 1964.

BARROS, Manoel de. Memórias Inventadas: A Infância. São Paulo: Planeta, 2003.

BARBOSA, F.D. Vacaria dos Pinhais. Porto Alegre: Ed. EST, 1978.

BELTING, Hans. Antropologia da imagem. Lisboa: KKYM+EAUM, 2014, pp. 9-116. 
BOLDRINI, Ilsi. (org). Biodiversidade dos campos do planalto das araucárias. Brasília: MMA, 2009.

CORRÊA, Roberto Lobato e Rosendahl Zeny (Org.). Paisagem, Tempo e Cultura. Rio de Janeiro: Ed. UERJ, 1998.

COSTA, Licurgo. O continente das Lagens. Florianópolis: Fundação Catarinense de Cultura, 1982

CLAVAL, Paul. Geografia Cultural: O Estado da Arte. In: CORRÊA, Roberto Lobato; ROSENDHAL, Zeny (org). Manifestações da Cultura no Espaço. Rio de Janeiro: UERJ, 1999a. p.5997.

DIDI- HUBERMAN. Cascas. São Paulo: Ed. 34, 2017.

HALBWACHS, Maurice. A memória coletiva. São Paulo: Centauro, 2015.

EHLKE, Cyro. A conquista do Planalto Catarinense: Bandeirantes e tropeiros no sertão de Curitiba. RJ: Ed. Laudes, 1973.

HERBERTS, Ana Lucia. Analise Arqueológica das estruturas viárias do caminho das tropas em Santa Catarina. Revista Tempos Acadêmicos. no 10, 2012.

HOLZER, Wether. Paisagem, Imaginário, Identidade: Alternativas Para o Estudo Geográfico. In: CORREAA, Roberto Lobato; ROSENDHAL, Zeny (org). Manifestações da Cultura no Espaço. Rio de Janeiro: UERJ, 1999. p.149-168.

KOSELLECK, Reinhart. "'Espaço de experiência' e 'horizonte de expectativa': duas categorias históricas" In: Futuro Passado: Contribuição à semântica dos tempos históricos. Rio de Janeiro: Contraponto/Editora da PUC-RJ, 2006.

LACAN. A esquize do olho e do olhar, in: Seminário 11, pp. 69-78

MELO V. Paisagem e simbolismo. In: ROSENDHAL, Z.; CORRÊA, R. (org.). Paisagem, imaginário espaço. Rio de Janeiro: EdUERJ, 2001.

MORAES, Antônio C. R. Ideologias Geográficas: Espaço, cultura e política no Brasil. São Paulo: HUCITEC, 1996.

OLIVEIRA, O. A. . Os Protagonistas da História dos Campos Neutrais. Biblos (Rio Grande), v. 1, p. 69-80, 2010.

PELUSO JUNIOR, Victor Antônio. Latifúndios e Minifúndios no Estado de Santa Catarina. Florianópolis: UFSC, 1971.

PIAZZA, Walter F. Santa Catarina: Sua história. Florianópolis: UFSC, 1983. 
SANTOS, Fabiano Teixeira dos. A Casa do Planalto Catarinense: Arquitetura rural e urbana nos campos de Lages, séculos XVIII e XIX . Lages (SC): Super Nova, 2015.

SANTOS, Milton. Espaço e sociedade: ensaios. Petropolis: Vozes, 1979. 156p

SANTOS, Lucy W. Estação Agronômica e de Veterinária do Estado: Uma abordagem sobre o início da pesquisa agrícola em Santa Catarina. Florianópolis: UFSC, 1998.

SARTRE, Jean-Paul. A Imaginação. IN: Textos Selecionados. São Paulo: Abril Cultural, 1984.

SAUER, C.O. A morfologia da Paisagem. In: CORREAA, R.L; ROSENDAHL, Z. (Org.). Paisagem, tempo e cultura. Rio deJaneiro: EdUERJ, 1998.

SILVA, Adriana Fraga. Estratégias materiais e espacialidades: Uma arqueologia da paisagem do Tropeirismo nos Campos de Cima da Serra/RS. Porto Alegre: PUCRS, 2006. (Dissertação).

SOUZA, Marcelo Lopes. Os conceitos fundamentais da pesquisa sócio-espacial. Rio de Janeiro: Bertrand Brasil, 2013.

SCHULER SOBRINHO, Octacilio. Taipas: Origem do homem do Contestado. Florianópolis: Letras Contemporâneas, 2000. 